\title{
Antismoking forces gather momentum in Canada ...
}

Christmas came early for beleaguered antismoking forces in Canada last year. On 28 November the Canadian government announced long-promised controls on tobacco.

"These are very important steps," said Cynthia Callard, executive director of Physicians for a Smoke Free Canada. Of particular interest to Callard are proposals that for the first time will allow regulation of cigarette constituents such as nicotine and tar. In addition, tobacco advertising on television, radio, billboards and counter-top displays in stores will be banned, although advertising will be allowed in publications aimed at adults and through direct mail.

Health Minister David Dingwall stopped short of banning sponsorship of sporting and cultural events by tobacco companies, but the display of brand names during such events will be severely limited. Antismoking groups, including the Canadian Medical Association, Canadian Cancer Society and Non-Smoker's Rights Association, generally lauded the new regulations, but were unhappy that they did not completely ban advertising and sponsorships or Canadian doctor lays flowers at the "Tomb of the Unknown Smoker."

\section{UNAVAILABLE FOR COPYRIGHT REASONS}

smokers, consumption increased, particularly among price-sensitive teens. Then, in October 1995, the Supreme Court of Canada ruled existing advertising regulations unconstitutional.

The tobacco companies, who were well aware of government commitments to restrictive legislation, greeted these fortunate events by adopting their own advertising code and trying to maintain a low profile. But the antismoking opposition soon howled that billboards were being placed close to schools and the advertisements were being aimed at the young, both contraventions of the companies' own code.
Antitobacco forces are under no illusion that it will be easy to get the new laws through Parliament; many present and former politicians have strong ties to the manufacturers. And if they are successful, there will inevitably be legal challenges. "The government seems to be proposing a regime that is extreme but ineffective, hugely expensive ... and quite possibly illegal," warned Marie-Josée Lapointe, spokeswoman for the Canadian Tobacco Manufacturers Council, giving an indication of the tobacco industry's willingness to continue the fight even if legislation is passed.

TERRY MCALLISTER

Ottawa, Canada adopt their proposal to force cigarettes to be sold in generic packages without logos or colors.

However, given the major setbacks antismoking forces have suffered in recent years, and the intense lobbying by major tobacco companies in Canada to try to stave off the proposals, Garfield Mahood, executive director of the Non-Smoker's Rights Association was happy. "The minister has used up a lot of political capital just to get this far," he said, urging that the legislation be fast-tracked through Parliament.

That won't be easy. Existing tobacco regulation in Canada, once a model for other countries, has unraveled in the past few years. In 1994, faced with huge smuggling operations bringing 16 billion lowcost cigarettes into eastern Canada each year, cigarette taxes were slashed. The price of a pack of cigarettes dropped by half to US\$2.00 and, according to anti-

\section{... and in Australia}

Last 4 July, tobacco advocates and producers initiated legal action in Australia's Federal Court against the country's National Health and Medical Research Council (NHMRC), in an attempt to prevent the council from publishing its final report on the health effects of passive smoke.

The plaintiffs, who 矢 included the Tobacco Institute of Australia (TIA), Rothmans and Philip Morris (Australia) Ltd., charged that during the preparation of the draft report the NHMRC Working Party "failed to consider all relevant material as its terms of reference and the law require." One key objection was the exclusion of unrefereed research material supplied by TIA.

Although admitting that most Australian research on the effects of passive smoking was carried out in the home environment, and thus could not be directly extrapolated to the workplace, the NHMRC Working Party said there was enough evidence from research done elsewhere to conclude that passive smoking has a host of adverse health effects, including aggravation of asthma in children, increased risk of lower respiratory infections, and a higher risk of lung cancer and coronary heart disease.

According to government estimates, the cost of these effects to the Australian taxpayer is more than AU $\$ 20$ million a year. Therefore, the NHMRC has recommended making indoor workplaces and public areas smoke-free, isolating smokers from non- smokers in outdoor public places, providing separately ventilated dormitories for smokers and nonsmokers in institutions such as jails, implementing legislation that prohibits the exposure of children to passive smoking (both in private automobiles and child-care environments), and making the Olympic games (to be held in Sydney in the year 2000) smoke-free.

On 19 August, in response to the tobacco lobby's concern, the Court issued an injunction against publication of the NHM$\mathrm{RC}^{\prime}$ 's final report before the complaint would be heard by the federal court. This injunction not only affects publication of the report, but sets precedents in law and civil liberties, a fact that troubles many observers. For example, it is the first time that a statutory research body has been prevented from publishing its final report (in this case, the draft report is a working document that has no weight until officially published in final form). In addition, the TIA action prevented three members of the NHMRC Working party from speaking at an October seminar on passive smoking organized in part by the Australian Medical Association (AMA).

Because only 25 percent of Australians still smoke, the AMA believes the tobacco industry is fighting for its life. "The tobacco industry can no longer deny the lethal effects of active smoking. What it is now trying to do is attack research showing that passive smoking is also harmful," AMA president Keith Woollard told the passive smoking seminar delegates.

ELIZABETH BAN Sydney, Australia 